\title{
Türkiye'de Biber Üretimi, Dış Ticareti ve Rekabet Gücü
}

\author{
İsmail GÜVENÇ \\ Kahramanmaraş Sütçü İmam Üniversitesi, Ziraat Fakültesi, Bitkileri Bölümü, Kahramanmaraş \\ https://orcid.org/0000-0002-4686-9487 \\ $\triangle$ : guvencis46@gmail.com
}

\section{ÖZET}

Bu çalışmada Türkiye sebzeciliğinde önemli bir yere sahip olan biber üretimi, dış ticareti ve rekabet gücü incelenmiştir. Türkiye'de 2.7 milyon ton civarında biber (taze ve kuru) üretilmektedir. 2017 verilerine göre Dünya taze biber üretiminin \% 7.23'ü Türkiye'de üretilmiştir. Son yıllarda Türkiye'nin toplam biber ihracatı 97.31 bin ton; ithalatı ise 251 ton kadardır. Türkiye'nin biberde rekabet gücü (karşılaştırmalı üstünlüğü) 2012-2015 döneminde zayıf iken, 2016 döneminde ise orta derecede (2.039) bir rekabet gücünün olduğu tespit edilmiştir. Türkiye'nin biber üretiminde alacağı önlemlerle üretim, yeterlilik, ihracatta rekabet gücünü artırması mümkündür.

\section{Araştırma Makalesi}

\section{Makale Tarihçesi}

Geliş Tarihi : 23.07.2019

Kabul Tarihi : 27.09.2019

\section{Anahtar Kelimeler}

Biber

Üretim

Ihracat

Rekabet gücü

\section{The Production, Foreign Trade and Comparative Advantages of Peppers in Turkey}

\section{ABSTRACT}

In this study, the production, foreign trade and comparative advantages of peppers, which has a significant value in Turkey, was evaluated. Pepper is produced about 2.7 million tons (dry or green) in Turkey. According to 2017 data, Turkey has $7.23 \%$ of total pepper world production. In recent years, peppers exports and imports in Turkey were respectively 97.31 thousand tons and 251 tons. While Turkey's comparative advantages in peppers were weak during the period of 2012-2015, levels of competitiveness was medium $(2,039)$ in 2016. Therefore, it is possible to increase production, qualification, and comparative advantages in export by means of the measures taken in peppers.

\section{Research Article}

$\begin{array}{ll}\text { Article History } \\ \text { Received } & : 23.07 .2019 \\ \text { Accepted } & : 27.09 .2019\end{array}$

Keywords

Peppers

Production

Export

Comparative advantages

To Cite : Güvenç İ 2019. Türkiye'de Biber Üretimi, Dış Ticareti ve Rekabet Gücü. KSÜ Tarım ve Doğa Derg 23 (2): $441-445$. DOI: 10.18016/ ksutarimdoga.vi.595512.

\section{GIRIŞ}

Biber (Capsicum annuum L.) Türkiye'de yaygın olarak üretilen sebzelerde biri olup farklı varyeteleri bulunmaktadır. Biberin olgunlaşmamış veya olgun meyveleri taze veya işlenmiş (biber salçası, baharat veya turşu) olarak tüketilmektedir. 2018 yılı verilerine göre Türkiye'de 2.782.354 ton biber üretimi vardır. Bu üretimin \% 8,17’ini kuru biber; \% 91.83'ünü ise taze biber üretimi meydana getirmektedir. (Anonim, 2018). Bu veriler Türkiye'de biberin taze tüketimi yanında işlenerek mamul ürün olarak değerlendirilmesinin de önemli olduğunu göstermektedir. $\mathrm{Bu}$ açıdan değerlendirildiğinde toplam biber üretiminin $\%$ 48.61'lik kısmının sanayiye işlenen (kuru ve taze salçalık) biberlerin oluşturduğunu söylemek mümkündür. Biber Ege, Marmara ve güney illerimizde biber salçası, kurutmalık veya toz/pul kırmızıbiber (baharat) üretiminde yetiştiricilik ve işleme aşamalarında yoğun insan emeğine ihtiyaç duyulması nedeniyle önemli bir istihdam kaynağıdır (Güvenç 2017). Önemli biber üretici illerimiz arasında,
Bursa, Samsun, İzmir, Hatay, Gaziantep, Kilis ve Kahramanmaraş yer almaktadır.

Türkiye'de sebze üretimi ve iç ve dış pazarlarda değerlendirme durumu önceki çalışmalarda da incelenmiştir (Alan ve Güvenç 1992; Güvenç ve Alan, 1994a ve b; Kaymak vd., 2005; Güvenç ve Kaymak, 2008). Bu incelemelerde ortaya konan ve günümüzde de geçerli olan durum üretilen sebzenin tamamının iç pazarlarda değerlendiril(e)memesidir. $\mathrm{Bu}$ nedenle sebzelerin üretiminin yanı sıra pazarlanmasında da özellikle dış ticaret imkânları önemlidir.

Türkiye'nin, geleneksel ihraç tarım ürünlerinin çoğunda (incir, kuru üzüm, findık, fıstık ve kuru kayısı) karşılaştırmalı üstünlüğünün var olduğu bildirilmiştir (Erkan, 2012). Ancak Türkiye'de üretilen sebze türlerinin Türkiye'nin sebze ihracatındaki uluslararası rekabet gücünü ifade eden karşılaştırmalı üstünlüklerini (uluslararası rekabet gücünü) ortaya koyan araştırma sayısı oldukça sınırlıdır. Türkiye'nin üretim ve ihracatına ağırlık verme(me)si önerilen bazı 
sebze ürünleri; 1993-2012 dönemini kapsayan bir araştırma ile karşılaştırmalı üstünlükler teorisi ve en uygun kaynak tahsisi yöntemleri doğrultusunda belirlenmiştir (Erkan ve ark., 2015). Farklı ülkelerin sebze ihracatında durumunu ortaya koymak için yapılan çalışmalarda Macaristan'ın karşılaştırmalı üstünlüğe sahip olduğu (Fertő ve Hubbard 2001); Slovenya'nın ise karşılaştırmalı üstünlüğünün olmadığ̣ (Bojnec ve Fertő 2006) belirlemiştir.

Biberde ihracat ve rekabet gücünü inceleyen çalışmaların oldukça sınırlı olması konunun ayrıntılı incelenmesini zorunlu kılmaktadır. Bu nedenlerle bu incelemede Türkiye'de işlenmiş ve taze olarak değerlendirilen önemli bir sebze olan biberin üretimi, dış ticareti ve rekabet gücü değerlendirilmiştir.

\section{MATERYAL ve YÖNTEM}

Bu çalışmada, Türkiye'nin biber üretimi, rekabet gücü ve diş ticaret durumunu tespit edilmesi amaciyla Birleşmiş Milletler Gıda ve Tarım Örgütü'nün (FAO/FAOSTAT: Anonymous 2019) istatistikleri kullanılmıştır. Çalışmada Türkiye İstatistik Kurumu (TUIK: Anon., 2018) ile Tarım ve Orman Bakanlığı Bitkisel Üretim Genel Müdürlüğünnün (BÜGEM)/(Anon., 2019) ilgili verilerinden de yararlanılmıştır.

TÜİK veri tabanında üretim ile ilgili kullanılan biber istatistikleri şu isim ve kodlar ile yer almaktadır: Biber-kuru, işlenmemiş (01.28.12.00.00.); bibersalçalık, kapya (01.13.31.00.01.); biber-dolmalık (01.13.31.00.02.); biber-sivri (01.13.31.00.03.); biberçarliston (01.13.31.00.04.). TÜIKK veri tabanında bu kodlu verilerin toplamı FAOSTAT istatistiklerinde taze biber (Chillies and peppers, green) verileri ile uyumludur.

Çalışmada Birleşmiş Milletler Gıda ve Tarım Örgütü'nün (FAO) 401 ürün kodlu (Item Code) taze biber (Chillies and peppers, green) istatistikleri de kullanılmıştır. Taze bibere ait bu koddaki Dünya (Area Code 5000) ve Türkiye'nin (Area Code 223); ihracat (Element Code 5910) ve ithalatı miktarı (Element Code 5610) ve rekabet katsayısını hesaplamak için ihracat değerlerine (Element Code 5922) ait veriler kullanılmıştır.

Karşılaştırmalı Üstünlük Katsayısı: Balassa'nın Açıklanmış Karşılaştırmalı Üstünlük (AKÜ) katsayısı (Balassa Endeksi), karşlaştırmalı üstünlükleri ticaret sonrası verilere dayalı olarak ölçmektedir. Ülkenin belli mallarda (sektörlerde) karşılaştırmalı üstünlüğe sahip olup olmadığını ortaya koymaya çalışan Balassa Endeksi; herhangi bir malın (sektörün) ülkenin toplam ihracatındaki payının, söz konusu malın (sektörün) dünyanın (ya da bölgenin) toplam ihracatındaki payına oranını ifade eder. Diğer bir ifadeyle Balassa Endeksi; ülkenin bir maldaki (sektördeki) yurtiçi uzmanlaşmasını (AKÜ endeksinin payı), dünyanın (ya da bölgenin) uzmanlaşmasıyla karşılaştırır (Bashimov, 2016). Daha açık bir anlatımla açıklanmış karşılaştırmalı üstünlükler katsayısının (AKÜ endeksi) pay kısmı, malın (sektörün) ulusal ihracattaki payını (\%); payda kısmı ise, söz konusu malın (sektörün) dünya toplam ihracatındaki payını temsil etmektedir (Mykhnenko, 2005; Erkan ve ark., 2015; Bashimov, 2016).

Rekabet gücünü göstermek amacıyla Balassa'nın AKÜ katsayısını 4 aşamada sinıflandırmaktadır (Hinloopen, ve Marrewijk, 2001): (1)- Rekabet gücü yoktur: $0<$ AKÜ $\leq 1 ;(2)$ - Zayıf bir rekabet gücü vardır: $1<\mathrm{AKÜ} \leq 2$; (3)- Orta derecede rekabet gücü vardır: -2 $<$ AKÜ $\leq 4$; (4)- Güçlü bir rekabet gücü vardır: $4<$ AKÜ.

Herhangi bir tarımsal ürünün açıklanmış karşılaştırmalı üstünlük katsayısının 1'den büyük olması, incelenen ülkenin belirli bir dönemde incelenen ürünün ihracat payının, aynı dönemde toplam dünya ihracatındaki payından büyük olduğunu ifade etmektedir (Bashimov, 2016). Diğer bir ifadeyle, ülke söz konusu tarımsal ürün ihracatında rekabet gücüne sahiptir ve uzmanlaşmıştır.

Söz konusu endekse göre; lnAKÜjkt $>0$ ise Ülke tarım ürünü ihracatında uzmanlaşmıştır ve ülkenin söz konusu üründe ticaret performansı yüksektir (Erkan ark., 2015).

Çalışmada kurumların veri tabanlarından elde edilen veriler EXCEL programından yararlanarak ihtiyaç duyulan yüzde (\%) ve toplama gibi hesaplamalar yapılmıştır. AKÜ katsayısının belirlenmesinde önceki araştırıcıların hesaplama tekniklerinden yararlanılmıştır (Erkan ve ark., 2015; Bashimov, 2016).

\section{BULGULAR}

\section{Üretim}

2004-2017 döneminde Dünya ve Türkiye'deki taze biber üretimindeki değişim Çizelge 1'de verilmiştir. Dünya biber üretimi 2004'de 24.6 milyon ton iken \% 46.56 oranında artarak 2017'de 36.09 milyon ton olarak gerçekleşmiştir. Türkiye dünya taze biber üretiminde \% 7.23'lük bir paya sahiptir. Türkiye biber üretimi 2004'de 1.7 milyon ton iken 2017'de 2.60 milyon tona yükselmiştir. Türkiye'nin biber üretimi incelenen 2004-2017 döneminde toplamda düzenli olarak artmıştır. Nitekim 2004 üretimine göre 2017'de artış oranı \% 53.42'dir. Bu artış nüfus artışının da üzerindedir. Şöyle ki Türkiye nüfusunun 2005 yılına göre (67.7 milyon) \% 19.09 artışla 2018 yılında 82.0 milyon olduğu belirlenmiştir. Türkiye'nin nüfus artış hızı dikkate alındığında fert başına düşen biber üretimindeki artış toplam biber üretimindeki artıştan daha azdır. Nitekim taze biber üretimi 2005 yılında fert başına 26-27 kg kadar iken 2018 yılında \% 27.74 artışla 33-34 kg'a yükseldiği belirlenmiştir (Çizelge 2 ve 3$)$. 
Çizelge 1. 2004- 2017 döneminde Dünya ve Türkiye'de biber üretimi.

Table 1. Production of peppers for the World and Turkey in 2004- 2017.

\begin{tabular}{|c|c|c|c|c|c|}
\hline $\begin{array}{c}\text { Yil } \\
\text { Years }\end{array}$ & $\begin{array}{c}\text { Dünya (Ton) } \\
\text { The World (Tone) }\end{array}$ & $\begin{array}{c}\text { Değişim (\%) } \\
\text { Changing (\%) }\end{array}$ & $\begin{array}{c}\text { Türkiye (Ton) } \\
\text { Turkey (tone) }\end{array}$ & $\begin{array}{c}\text { Değişim (\%) } \\
\text { Changing (\%) }\end{array}$ & $\begin{array}{c}\text { Pay (\%) } \\
\text { Ratio \% }\end{array}$ \\
\hline 2004 & 24.626 .357 & 100.00 & 1.700 .000 & 100.00 & 6.90 \\
\hline 2005 & 25.353 .715 & 102.95 & 1.829000 & 107.59 & 7.21 \\
\hline 2006 & 26.700 .847 & 108.42 & 1.842 .175 & 108.36 & 6.90 \\
\hline 2007 & 27.427 .243 & 111.37 & 1.757 .226 & 103.37 & 6.41 \\
\hline 2008 & 28.114 .953 & 114.17 & 1.796 .177 & 105.66 & 6.39 \\
\hline 2009 & 28.760 .193 & 116.79 & 1.837 .003 & 108.06 & 6.39 \\
\hline 2010 & 29.680 .830 & 120.52 & 1.986 .700 & 116.86 & 6.69 \\
\hline 2011 & 30.255 .631 & 122.86 & 1.975 .269 & 116.19 & 6.53 \\
\hline 2012 & 30.961 .594 & 125.73 & 2.042 .360 & 120.14 & 6.60 \\
\hline 2013 & 31.268 .030 & 126.97 & 2.159 .348 & 127.02 & 6.91 \\
\hline 2014 & 32.126 .171 & 130.45 & 2.127 .944 & 125.17 & 6.62 \\
\hline 2015 & 33.177 .009 & 134.72 & 2.191 .888 & 128,93 & 6.61 \\
\hline 2016 & 34.592 .680 & 140,47 & 2.457 .822 & 144.58 & 7.11 \\
\hline 2017 & 36.092 .631 & 146.56 & 2.608 .172 & 153.42 & 7.23 \\
\hline
\end{tabular}

Kaynak: FAOSTAT Veri tabanından yararlanarak hazırlanmıştır (Anonymous 2019).

Çizelge 2. Türkiye'de 2004-2018 döneminde biber üretim miktarı (Ton/Yıl).

Table 2. Quantity of production of peppers for Turkey in 2004-2018.

\begin{tabular}{|c|c|c|c|c|c|}
\hline $\begin{array}{c}\text { Yll } \\
\text { Years }\end{array}$ & $\begin{array}{c}\text { Biber, Kuru } \\
\text { Peppers, dry }\end{array}$ & $\begin{array}{c}\text { Salçalık, Kapya } \\
\text { Capia peppers }\end{array}$ & $\begin{array}{c}\text { Biber Dolmalık } \\
\text { Peppers, bell }\end{array}$ & $\begin{array}{c}\text { Biber, Sivri } \\
\text { Long green } \\
\text { peppers }\end{array}$ & $\begin{array}{c}\text { Biber Carliston } \\
\text { Sweet peppers }\end{array}$ \\
\hline 2004 & 30.000 & 615.000 & 375.000 & 710.000 & - \\
\hline 2005 & 45.000 & 685.000 & 400.000 & 744.000 & - \\
\hline 2006 & 45.861 & 673.981 & 392.617 & 775.577 & - \\
\hline 2007 & 67.213 & 674.788 & 357.246 & 725.192 & - \\
\hline 2008 & 60.000 & 690.531 & 371.050 & 734.596 & - \\
\hline 2009 & 196.900 & 700.038 & 384.273 & 752.692 & - \\
\hline 2010 & 186.272 & 782.173 & 387.626 & 816.901 & - \\
\hline 2011 & 162.125 & 730.493 & 364.930 & 879.846 & - \\
\hline 2012 & 165.527 & 748.422 & 383.213 & 910.725 & - \\
\hline 2013 & 198.636 & 814.372 & 398.470 & 946.506 & - \\
\hline 2014 & 186.291 & 829.809 & 391.009 & 907.126 & 104.364 \\
\hline 2015 & 204.131 & 879.775 & 393.109 & 919.004 & 115.568 \\
\hline 2016 & 228.531 & 957.030 & 418.435 & 967.466 & 114.891 \\
\hline 2017 & 179.264 & 1.107 .713 & 420.904 & 945.361 & 134.194 \\
\hline 2018 & 227.380 & 1.128 .060 & 397.175 & 930.349 & 99.390 \\
\hline Pay-2018(\%) & 8,17 & 40,54 & 14,27 & 33,44 & 3,57 \\
\hline
\end{tabular}

Kaynak: TÜİK veri tabanından yararlanarak hazırlanmıştır (Anon., 2018).

Türkiye'nin biber üretiminin kuru ve taze üretim olarak dağılımı Çizelge 2'de sunulmuştur. Taze biber üretimi salçalık, dolmalık, sivri ve çarliston olarak ayrılmaktadır. Türkiye'de 2018 yılı verilerine göre toplam 2.782.354 ton biber üretimi vardır. Bu yılın verilere göre miktar olarak üretimin \% 8.17'ini kuru biber üretimin oluştururken taze biber üretimi \% 91.83'lük bir paya sahiptir. Başka bir açıdan ise sanayiye işlenen (kuru ve salçalık) biber üretimi ise \% 48.61'lik bir paya sahiptir. Bu veriler biberin taze tüketimi yanında işlenerek mamul ürün olarak önemini de göstermektedir.

\section{Dış Ticaret}

Dünya taze biber dış ticaretinde 3.0-3.0 milyon ton kadar bir ürün ihracatı veya ithalatı söz konusudur (Çizelge 4). Türkiye'nin biber ithalatı yıllara göre dalgalı bir durum göstermekle birlikte oldukça düşüktür. Dünya biber ihracatında Türkiye'nin payı 2012'de \% 2.39'i iken 2016 yllında \% 2.94'dir. Türkiye'nin biber ihracatı incelenen 2012-2016 döneminde artmıştır. Bu verilerde Türkiye'nin biber ihracatında olumlu yönde bir gelişmenin olduğunu göstermektedir. Türkiye ihracatı/ithalatı dengesi bakımında biberde azda olsa ihracat fazlası olan bir ülke konumundadır. 
Çizelge 3. Türkiye'de 2004-2018 döneminde nüfus ve biber üretimindeki değişim.

Table 3. Changing of population and peppers production in Turkey in 2004-2018.

\begin{tabular}{|c|c|c|c|c|}
\hline $\begin{array}{c}\text { Yll } \\
\text { Years }\end{array}$ & $\begin{array}{c}\text { Nüfus } \\
\text { Population }\end{array}$ & $\begin{array}{c}\text { Değişim (\%) } \\
\text { Changing (\%) }\end{array}$ & $\begin{array}{c}\text { Biber Üretimi (Kg/Fert) } \\
\text { Peppers production (kg/Person) }\end{array}$ & $\begin{array}{c}\text { Değişim (\%) } \\
\text { Changing (\%) }\end{array}$ \\
\hline 2005 & 68.860 .539 & 100.00 & 26.56 & 100.00 \\
\hline 2006 & 69.729 .967 & 101.26 & 26.42 & 99.46 \\
\hline 2007 & 70.586256 & 102.51 & 24.89 & 93.73 \\
\hline 2008 & 71.517100 & 103.86 & 25.12 & 94.56 \\
\hline 2009 & 72.561312 & 105.37 & 25.32 & 95.32 \\
\hline 2010 & 73.722988 & 107.06 & 26.95 & 101.46 \\
\hline 2011 & 74.724269 & 108.52 & 26.43 & 99.52 \\
\hline 2012 & 75.627384 & 109.83 & 27.01 & 101.67 \\
\hline 2013 & 76.667864 & 111.34 & 28.16 & 106.04 \\
\hline 2014 & 77.695904 & 112.83 & 27.39 & 103.11 \\
\hline 2015 & 78.741053 & 114.35 & 27.84 & 115.94 \\
\hline 2016 & 79.814871 & 115.91 & 30.79 & 121.51 \\
\hline 2017 & 80.810 .525 & 117.35 & 32.28 & 127.74 \\
\hline 2018 & 82.003 .882 & 119.09 & 33.93 & \\
\hline
\end{tabular}

Kaynak: TUİK veri tabanından yararlanarak hazırlanmıştır (Anon., 2018)

Türkiye'nin biber ihracatı 2012'de 74.9 milyon dolar iken 2016 'da 90.0 milyon dolara yükselmiştir (Çizelge 5). Aynı yıllarda Türkiye'nin değer olarak dünya ihracatındaki payı ise sırasıyla \% 1.69 ve \% 1.82 olarak belirlenmiştir. Türkiye'nin değer olarak dünya ihracatındaki payı miktar olarak ihracatından daha düşüktür. $\mathrm{Bu}$ durum dış pazar fiyatlarının irdelenmesini gerektirmektedir.

\section{Rekabet Gücü}

Türkiye'nin biberde dış ticaretinde rekabet gücü 20122016 döneminde incelenmiştir. $\mathrm{Bu}$ dönemde
Türkiye'nin ihracatta rekabet gücü var olup, 20122015 döneminde zayıf; 2016 'da ise orta derecede rekabet gücünün var olduğu belirlenmiştir (Çizelge 5). $\mathrm{Bu}$ katsayının 1-2 arasında olması zayıf; 2 ile 4 arasında olması ise bir ülkenin orta derecede ihracatında karşılaştırmalı üstünlüğe yani rekabet gücüne sahip olduğunu göstermektedir (Hinloopen, ve Marrewijk 2001). Bu çalışmadan elde edilen bulgular Türkiye'nin rekabet gücünün 2012-2016 döneminde zayıf/orta derecede olsa da var olduğunu ancak 2016 yılında ise orta derecede avantajının olduğunu göstermektedir (Çizelge 5).

Çizelge 4. Dünya ve Türkiye'nin biberde dış ticareti miktarı (Ton/yıl).

Table 4. Quantity of foreign trade of peppers for the World and Turkey (Tones/Year).

\begin{tabular}{|c|c|c|c|c|c|}
\hline & \multicolumn{2}{|c|}{ Dünya (The World) } & \multicolumn{2}{|c|}{ Türkiye (Turkey) } & \multirow{2}{*}{$\begin{array}{c}\text { Dünya İhracatında Türkiye'nin Payı (\%) } \\
\text { Percentage of Turkey in the World } \\
\text { export (\%) }\end{array}$} \\
\hline $\begin{array}{l}\text { Yil } \\
\text { Years }\end{array}$ & $\begin{array}{c}\text { İhracatı } \\
\text { Export }\end{array}$ & $\begin{array}{l}\text { Ithalat } \\
\text { Import }\end{array}$ & $\begin{array}{l}\text { İhracati } \\
\text { Export }\end{array}$ & $\begin{array}{l}\text { İthalat } \\
\text { Import }\end{array}$ & \\
\hline 2012 & 2.918 .541 & 2.880 .246 & 69.727 & 7 & 2.39 \\
\hline 2013 & 3.002 .741 & 2.927 .073 & 68.122 & 1712 & 2.27 \\
\hline 2014 & 3.369 .674 & 3.097 .021 & 81.568 & 197 & 2.42 \\
\hline 2015 & 3.194 .784 & 3.087 .808 & 88.022 & 67 & 2.76 \\
\hline 2016 & 3.314 .149 & 3.243 .207 & 97.314 & 251 & 2.94 \\
\hline
\end{tabular}

Kaynak: FAOSTAT veri tabanından yararlanarak hazırlanmıştır (Anonymous 2018) .

Çizelge 5. Türkiye'de biberde toplam ihracat değeri ve rekabet katsayısı.

Table 5. Export values and comparative advantages of peppers in Turkey.

\begin{tabular}{|c|c|c|c|c|c|}
\hline $\begin{array}{c}\text { Yll } \\
\text { Years }\end{array}$ & $\begin{array}{c}\text { Dünya } \\
\text { The World (1000 US\$) }\end{array}$ & $\begin{array}{c}\text { Türkiye } \\
\text { (1000 dolar) } \\
\text { Turkey (1000 US\$) }\end{array}$ & $\begin{array}{c}\text { Türkiye'nin Payl } \\
(\%) \\
\text { Percentage of } \\
\text { Turkey (\%) }\end{array}$ & $\begin{array}{c}\text { Rekabet katsaylsı } \\
\text { Comparative } \\
\text { advantages }\end{array}$ & $\begin{array}{c}\text { Üstünlük } \\
\text { Derecesi } \\
\text { Degree of } \\
\text { superiority }\end{array}$ \\
\hline 2012 & 4.444 .460 & 74.921 & 1.69 & 1.980 & Zayıf \\
\hline 2013 & 4.959 .269 & 82.234 & 1.66 & 1.999 & Zayıf \\
\hline 2014 & 4.803 .120 & 79.979 & 1.67 & 1.947 & Zaylf \\
\hline 2015 & 4.525 .720 & 77.863 & 1.72 & 1.972 & Zaylf \\
\hline 2016 & 4.940 .931 & 90.019 & 1.82 & 2.039 & Orta \\
\hline
\end{tabular}

Kaynak: Anonymous 2018 ve Anon., 2018 ve 2019 verilerinden yararlanarak hazırlanmıştır. 


\section{SONUÇ}

Bu çalışmada Türkiye'nin hem toplamda hem de fert başına düşen biber üretim miktarında düzenli bir artışın olduğu belirlenmiştir. Bununla beraber biber ihracatında miktar ve değer olarak bir artma vardır. $\mathrm{Bu}$ gelişmeler biberde ihracatta rekabet gücünü de etkilemiştir. Nitekim 2012-2015 döneminde ihracatta rekabet gücünün zayıf; 2016 yılında ise rekabet gücünün orta derecede olduğu (avantajının var olduğu) tespit edilmiştir.

Sahip olduğu ekolojik şartlar biber üretimine oldukça uygun olan (Güvenç 2017) Türkiye; bu potansiyelini iç ve dış pazar ihtiyaçlarını karşılamak için daha etkin değerlendirmesi mümkündür. Bu amaçla üretim ve pazarlama aşamalarında girdi maliyetlerinin azaltılması, ambalajlama ve standardizasyon gibi gerekli tedbirler alınmalıdır.

\section{Çıkar Çatışması Beyanı}

Makale yazarı herhangi bir çıkar çatışması olmadığını beyan eder.

\section{KAYNAKLAR}

Alan R, Güvenç İ 1992. Türkiye'nin Sebze İhracatına Genel Bir Bakış. Tarımda Kaynak Dergisi, 1 (19-2): 15-17.

Anonymous 2019. Food and Agriculture Organization of the United Nations (FAO). FAOSTAT, http://www.fao.org/faostat/en/\#data/QC. (Erişim Tarihi: 11.06.2019).

Anonim 2018. Bitkisel Üretim İstatistikleri. TUİK, http://www.tuik.gov.tr/ PreTablo.do?alt_id=1001. (Erişim Tarihi: 01.06.2019).

Anonim 2019. Bitkisel Üretim İstatistikleri. Tarım ve Ormancılık Bakanlığı Bitkisel Üretim Genel Müdürlüğü (BUGEM), https://www.tarim.gov.tr/ BUGEM/ Menu/9/Veriler. (ErişimTarihi: 03.04.2019).

Bashimov G. 2016. Türkiye'nin Domates İhracat Performansı ve Rekabet Gücü. Alinteri Journal of Agriculture Sciences . 31(2): 1-8.
Bojnec S, Fertő I 2006. Does Comparative Advantages in Agro-Food Trade Matter for Multifunctional Rural Development: The Case of Hungary and Slovenia. Journal of Central European Agriculture, 7 (3): $583-586$.

Erkan B 2012. BRIC Ülkeleri ve Türkiye'nin İhracat Uzmanlaşma ve Rekabet Düzeylerinin Karşılaştırmalı Analizi. Ekonomik ve Sosyal Araştırmalar Dergisi, 8 (1):101-131.

Erkan B, Arpacı BB, Yaralı F, Güvenç İ 2015. Türkiye'nin Sebze İhracatında Karşlaştırmalı Üstünlükleri. KSÜ Doğa Bil. Dergisi, 18(4): 70-76.

Fertő I, Hubbardn LJ 2001. Regional Comparative Advantage and Competitiveness in Hungarian AgriFood Sectors. 77th EAAE Seminar / NJF Seminar No. 325, August 17-

Güvenç I, Kaymak HC 2008. Türkiye'de Sebze Üretimi ve Tüketimindeki Değişme, Gereksinim ve Projeksiyon. Alınteri, 15 (B): 40-45.

Güvenç İ, 2017. Sebzecilik: Temel Bilgiler, Muhafaza ve Yetiştiricilik. Nobel Yayınları, S: 288.

Güvenç İ, Alan R 1994a. Türkiye'nin Avrupa Topluluğu Ülkelerine Sebze İhracatı. Atatürk Üniversitesi Ziraat Fakültesi Dergisi, 25, (1) :94-99.

Güvenç İ, Alan, R 1994b. Türkiye'nin Orta Doğu Ülkelerine Sebze İhracatı. Atatürk Üniversitesi Ziraat Fakültesi Dergisi, 25 (2): 269-274.

Hinloopen, J., Marrewijk, C.V. 2001. On the empirical distribution of the Balassa Index. Review of World Economics, Vol: 137, No:1, March 2001, P: 13.

Kaymak HC, Güvenç I, Dursun A, 2005. Türkiye'de Sebze Tarımının Mevcut Durumu, Önemli Bazı Gelişmeler ve Çözüm Önerileri. Atatürk Üniversitesi Ziraat Fakültesi Dergisi, 36, (2): 221228.

Mykhnenko, V. 2005. What Type of Capitalism in Eastern Europe? Institutional Structures, Revealed Comparative Advantages and Performance of Poland and Ukraine. Centre for Public Policy for Regions (CPPR) Discussion Paper, No:6, September 2005, p:27. 